\title{
Learning ecologies through a lens: Ontological, methodological and applicative issues. A systematic review of the literature
}

\section{Albert Sangrá, Juliana Elisa Raffaghelli (D) and Montse Guitert-Catasús}

Albert Sangrá is Academic Director of the UNESCO Chair in Technology and Education for Social Changeat the Open University of Catalonia. He is a researcher at the Edul@b research group and full professor at the Psychology and Educational Sciences Department. At the UOC, he has served as Director, Methodology and Educational Innovation until 2004, being in charge of the educational model of the university; Director of the M.Sc. program in Education and ICT (e-learning) (2006-2012), and Director of the eLearn Center (2012-2014). His main research interests are ICT uses in education and training and, particularly, the policies, organization, management and leadership of e-learning implementation, and its quality assurance, and the professional development for online teaching. Juliana Elisa Raffaghelli is an associate professor at the Faculty of Education and Psychology (Universitat Oberta de Catalunya). She served as principal investigator at the project "Professional Learning Ecologies for Digital Scholarship: Modernizing Higher Education by Supporting Professionalism," funded by the Ministry of Science, Technology and University of Spain under the program "Ramon y Cajal" (2018-2023). Her research interests are connected to faculty development for the modernization of higher education, data literacy and the use of closed and open data models for the improvement of educational processes. Montse Guitert-Catasús is Full professor of Psychology, an Education Studies at the Open University of Catalonia (UOC). She is Director of the Digital Literacy program and coordinator of the "ICT competences" course since its inception (1995). She is a professor at the Information and Knowledge Society Doctoral Programme; Master in Education and ICT (e-learning) and Master in Open Software at the UOC. Her research focuses on ICT uses in education and training and, particularly, online collaboration, online teacher training and Digital Competences. "Address for correspondence: Juliana Elisa Raffaghelli, Faculty of Psychology and Education Sciences, Universitat Oberta de Catalunya, Ramblas del Poblenou 156, 08018 Barcelona, Spain. Email: jraffaghelli@uoc.edu

\begin{abstract}
The concept of learning ecologies emerged in a context of educational change. While the "learning ecologies" construct has offered a broad semantic space for characterizing innovative ways of learning, it is also true that its potential to promote innovative educational interventions may have been hindered by this same broadness. Based on this assumption, in this paper the authors carried out a systematic review of the literature on learning ecologies with the aim of analysing: (1) the varying definitions given to the concept, including the ontological perspective underlying the phenomena studied; (2) the methodological approaches adopted in studying the phenomenon; and (3) the applications of the research on this topic. Throughout this analysis, the authors attempt to describe the criticalities of the existing research, as well as the potential areas of development that align well with the theoretical/ontological issues, methodological approaches and educational applications. The authors selected and analysed 85 articles, which they then classified in a set of 20 categories defined by them on a theoretical basis. Moreover, in order to triangulate the manual coding, a bibliometric map was created showing the co-citation activity of the 85 papers. The emerging picture showed significant variability in the ontological definitions and methodological approaches. In spite of this richness, few educational applications currently exist, particularly with regard to technology-enhanced learning developments. Most research is observational, devoted to describing hybrid (digital and on-site) learning activities
\end{abstract}




\section{Practitioner Notes}

What is already known about this topic

- The "learning ecologies" (LE) construct, widely adopted in the last 20 years, has offered a broad semantic space for characterizing innovative ways of learning.

- Several meanings have been assigned to this construct, which in some cases may conflict, ie, formal learning spaces and tools as LE, and informal learning across several contexts as LE.

What this paper adds

- The authors hypothesize that the power of the topic lies in its ability to support models and practices by overcoming the rigid separation between formal and informal learning. In fact, LE conceptualize the relationships between formal and informal as a continuum across several learning contexts, mediated by digital technologies.

- The paper introduces a systematic review of the literature on LE in which the inconsistencies in the definitions of the construct are analysed together with the methodological approaches and the research applications.

- Furthermore, the alignment between these three key elements has been studied in order to explain the weaknesses in realizing the full potential of the construct.

Implications for practice and/or policy

- Clearer definitions of LE may encompass new models and tools for analysing Technology-Enhanced Learning processes, supporting learning visibility and learners' awareness of the connections between the formal and the informal and vice versa.

- New research on digital tools for self-diagnosis and the development of learning ecologies might align with a perspective of self-directed and self-determined learning as a way to progress in lifelong learning.

that bridge the gap between the school and social spaces. Furthermore, many of the studies relate to the field of secondary education, with fewer studies exploring adult learning and higher education. The studies dealing with professional development relate mostly to teachers' continuing education. The authors conclude that the concept of learning ecologies could be used to address further experimental and design-based research leading to research applications if there is proper alignment between the ontological, methodological and applicative dimensions. The main potential of this strategy lies in the possibility of supporting learners by raising their awareness of their own learning ecologies, thereby empowering them and encouraging them to engage in agentic practices. This empowerment could help maintain and build new and better learning opportunities, which every learning ecology can incorporate, amidst the chaotic abundance that characterizes the digital society.

\section{Introduction}

The abundance of resources in the open and social Web has created unprecedented opportunities for learning. Key attributes such as "complex," "self-organized," "connected" and "adaptive" have been applied to depict the range of conditions underlying the learner's freedom of choice (Kop \& Fournier, 2010; Siemens, 2008). Moreover, the possibility of blending digital activities 
with on-site activities has led to the hybridization of learning contexts, where the learners experience a sort of "continuum" while searching for resources, cultivating relationships and engaging in activities to help them achieve their own, more or less, conscious learning goals (Esposito, Sangrà, \& Maina, 2013). Most of the literature produced in the last two decades in the field of technology-enhanced learning and online and blended learning has increasingly emphasized the centrality of the learner. The learner's intentionality to achieve knowledge and develop skills is the axis for interpreting the concept as a unified lived experience, as it makes sense of the multiple relationships and resources that comprise the learning activities. In this regard, the concept of personalized learning environments gained popularity, due to its operational alignment with the idea of learners' initiative, self-regulation, self-organization and leadership (Attwell, 2007; Dabbagh \& Kitsantas, 2012). However, other important constructs that characterize the changing landscape of learning in the digital era emerged. The conceptualizations emphasized the idea of learning every where and at any time, based on the rising phenomenon of access to the Internet and the use of mobile devices for learning. In this respect, "seamless learning” (Sharples, 2015; Wong, Milrad, \& Specht, 2015) and "ubiquitous learning” (Virtanen, Haavisto, Liikanen, \& Kääriäinen, 2018) led the way. This development further enriched the technological landscape while also contributing to the debate on formal, non-formal and informal learning (Mocker, 1983), since the digital tracking of activities and the digital presence on more informal spaces such as social media made the incidence and importance of unstructured forms of learning for lifelong learning more and more visible. A need was also detected to renew formal instruction by integrating or recognizing informal learning together with the formal curriculum (Cross, 2006; Kamenetz, 2010). The techno-educational debate was accompanied by other important pedagogical debates, which contributed to the idea of self-determination and free appropriation of the digital abundance, eg, heutagogy, or a pedagogy of adult selfdetermination and awareness of one's own abilities to continue learning (Blaschke, 2012).

Notwithstanding the impressive corpus of literature on technology-enhanced learning, as it stands today, the aforementioned constructs have shown their ability to describe specific areas of learning. Moreover, the ongoing hybridization of learning, both in terms of the medium (digital, on-site) and the type of learning (formal, non-formal, informal), reveals the need to generate new theories and constructs that are able to embrace the changing nature of the phenomenon in question, namely, lifelong learning. Another critical point to be considered relates to the so-called "pedagogy of abundance" (Kop, Fournier, \& Mak, 2011), where the learners select, freely and at their own convenience, the digital resources, tools and environments that they prefer. The somewhat naïve assumption "the more, the better" is a fallacy and represents a techno-determinist approach, which has already been criticized in the literature (Selwyn, 2011). Therefore, considering the situation described above, there appears to be a need to explore and develop constructs that can explain technology-enhanced, lifelong learning. Furthermore, these constructs should establish effective methodological approaches and enable knowledge transfer to applications in education.

In this paper, the authors will explore a concept that has been frequently adopted in the literature on pedagogical innovations: the "learning ecology" (hereinafter LE) construct, defined as the sum of contexts where the learner self-directs her activity, cultivating relationships and using, producing and sharing resources. Moreover, an LE is deemed hybrid, both in terms of the medium, since the lines between physical and virtual configurations are blurred, and in terms of type of learning, since it integrates formal and informal learning. While this concept has offered a broad semantic space capable of encompassing innovative ways of learning, it is also true that its potential to promote innovative educational interventions may have been hindered by this same 
broadness. Based on this assumption, in this paper the authors carry out a systematic review of the literature with the aim of analysing: (1) the varying definitions given to the concept, including the ontological perspective underlying LE; (2) the methodological approaches adopted to study the phenomenon; (3) the applications of the research results on this topic with regard to educational interventions. Throughout this analysis, the authors attempt to establish the criticalities of the existing research, as well as the potential areas of development which align with the theoretical/ontological issues, the methodological approaches and the educational applications.

\section{Background: The concept of LE in the literature}

The ecological perspective was adopted in the social sciences in the early eighties through Bateson's pioneering interdisciplinary approach to the study of human behaviour in his work "Steps to an Ecology of Mind" (Bateson, 1987). A little later, Bronfenbrenner (1994) characterized human development as a process based on interactions at several social levels in what he called "the ecological systems theory." In his approach, Bronfenbrenner described the individual's ability to appropriate several resources for competence development. While both the aforementioned authors see the sociocultural system as complex and multilayered and developing in the same way as an ecology does, Bronfenbrenner's perspective places importance on learner agency in relation to her engagement with self-development. Since the emergence of these two important theoretical contributions until the present day, the ecological approaches concerned with teaching and learning issues in the digital age have yielded a range of terms and conceptual definitions. These definitions range from those that are strongly linked to the legacy left by studies on biological ecosystems, which characterize the school, the classroom and the Web as ecosystems for learning, to those that treat the Web as a new kind of learning environment or as a component in a more complex entanglement of individuals and tools, which constitute ecological components (Esposito, Sangrà, \& Maina, 2015). Nonetheless, a common theme across several studies is the ecological perspective conceived as a cyclical, complex and emergent phenomenon (Haythornthwaite \& Andrews, 2011).

In her study on achieving technological fluency, Brigid Barron (2004) made an early and relevant contribution. She analysed how technological fluency was achieved across a set of contexts and in terms of resources, activities and relationships, which provided opportunities for learning in physical or virtual spaces (Barron, 2006). She compared the levels of expertise with the types of contexts and the frequency of activity within them. She then gave a definition of LE from a sociocultural perspective, in which the transitions of the individuals across a range of formal and informal contexts providing diverse learning opportunities (Barron, 2006) can improve the understanding of the interdependence of the institutional and personal levels in the educational use of emerging ICTs.

As in Barron's study, many authors have characterized LE as combinations of formal, non-formal and informal learning contexts (Wilkinson, Kemmis, Hardy, \& Edwards-Groves, 2009). Nevertheless, the term has often been adopted to describe the emergent dynamics of learning within the classroom (Crick, Mccombs, Haddon, Broadfoot, \& Tew, 2007) or within e-learning environments (Richardson, 2002). Moreover, the term has been used in several fields of education, including technologies and gender (Barron, 2004), ICT skills development (Barron, 2006), collaborative learning (Hodgson \& Spours, 2009), designs for learning with technologies (Luckin, 2010), learning resources for homeless populations (Strohmayer, Comber, \& Balaam, 2015), teachers' professional development (Sangrà, González-Sanmamed, \& Guitert, 2013; van den Beemt \& Diepstraten, 2016), personalized learning and lifelong learning (Maina \& González, 2016), youth civic engagement (Ige, 2017) and ubiquitous learning in higher 
education (Díez-Gutiérrez \& Díaz-Nafría, 2018). Also Jackson (2013) has to be taken into main consideration, as he explores the construct of learning ecologies and introducing the very interesting concept of lifewide learning. Although his studies are not as empirical as the ones mentioned before, they are experientially rich and have been inspirational for many empirical studies as conceptual basis.

While considered a powerful tool which has already been applied in several ways, the concept of LE for lifelong learning has to overcome some issues to fulfil its full potential. Firstly, there is an ontological problem posed by the different ways of defining LE as an empirical phenomenon (technological resources, digital spaces, learning networks, etc.) and in some cases based on subsidiary theories. Secondly, these differences have led to a variety of instruments and methods of study being adopted that require defining, including new educational research methods, such as public data-driven research (Kimmons \& Veletsianos, 2018), among others. Therefore, the researcher interested in applying this perspective might be puzzled by the variety of approaches and instruments. A systematic review of the literature on the topic, to our knowledge inexistent until now, might bring some light on the areas where deeper exploration is needed, and on the associations between research subtopics, instruments and the interpretation of empirical data for the advancement of the field.

\section{Methodology}

Study design and sampling

This paper provides a systematic review of the literature on the topic, based on the PRISMA workflow (Moher, Liberati, Tetzlaff, Altman, \& PRISMA Group, 2009). Systematic reviews entail a specific process of appraising, summarizing and communicating the literature, while dealing with otherwise unmanageable quantities of documents. Moreover, the process also attempts to control researcher bias in data collection and analysis (Petticrew \& Roberts, 2006). Following this approach, five scientific databases that index peer-reviewed research were scanned (full names and URLs are shown in Table 1). These databases were selected due to their coverage of: (1) peerreviewed empirical research; (2) social research; (3) educational research. Within each database, we adopted the query "Learning” AND "Ecolog*" without time or disciplinary constraints.

This search yielded 337 papers. From these, 133 were overlaps and, once eliminated, 260 papers were considered for the screening phase. In this phase, three researchers read the abstract and excluded the papers that were not relevant for the analysis envisaged. The exclusion criteria were: (1) Not a journal or conference paper; (2) Not empirical research; (3) No English language version available (for an international audience to follow the analysis with transparency); (4) Superficial usage of the LE concept: construct mentioned, but not used for or central to the research; (5) Dealing with ecologies as a topic in science education rather than a pedagogical approach; (6) Unavailable document (requested or searched via the Library). In this regard, some authors considered important by experts on the topic of LE, like N. Jackson (2016) have been published as conceptual books and their reference is frequently embedded in empirical research, which was targeted in this systematic review.

According to the scheme above, 180 papers were excluded and 85 papers were considered for final analysis. Figure 1 shows the PRISMA workflow.

Appendix 1 in supporting information shows the complete list of authors and papers selected.

\section{Data analysis}

As for the analysis, the papers were coded and classified into different categories, as defined by three authors, and further discussed in a session within an extended research group with eight 
Table 1: Database for the classification of articles

\begin{tabular}{|c|c|c|}
\hline Fields [Variables] & Description & Subfields [Codes assigned] \\
\hline Authors & Authors in the paper & \\
\hline Title & Publication title & \\
\hline Year & Year of publication & \\
\hline Source Title & $\begin{array}{l}\text { Journal, conference or other } \\
\text { information indicating the type } \\
\text { and context of publication }\end{array}$ & \\
\hline Cited by & $\begin{array}{l}\text { Number of authors citing the } \\
\text { publication under analysis }\end{array}$ & \\
\hline Document Type & Type of publication & Article, Conference Paper, Book Chapter \\
\hline $\begin{array}{l}\text { Publication } \\
\text { Source }\end{array}$ & $\begin{array}{l}\text { Scientific database where the } \\
\text { publication was found: Scopus } \\
\text { (www.scopus.com ), WOS (Web } \\
\text { of Knowledge, www.webof- } \\
\text { knowledge.com ), DOAJ } \\
\text { (Directory of Open Access } \\
\text { Journals, www.doaj.com), ERIC } \\
\text { (Education Resources } \\
\text { Information Center https://eric. } \\
\text { ed.gov/), EDITLIB (Learning \& } \\
\text { Technology Library, https:// } \\
\text { www.learntechlib.org/) }\end{array}$ & Presence [1]/Absence [0] \\
\hline Abstract & $\begin{array}{l}\text { Synthesis of the research, as } \\
\text { provided by the authors }\end{array}$ & \\
\hline Author Keywords & $\begin{array}{l}\text { Specific words describing the } \\
\text { content/focus of the research }\end{array}$ & \\
\hline Research Area & $\begin{array}{l}\text { The overarching disciplinary field } \\
\text { where the research can be } \\
\text { placed, based on Scopus and } \\
\text { WOS definitions }\end{array}$ & $\begin{array}{l}\text { Social Sciences, Computer Science, Health } \\
\text { Sciences, Engineering, Psychology, Arts \& } \\
\text { Humanities (including Linguistics) }\end{array}$ \\
\hline Type of Learning & $\begin{array}{l}\text { Characterization of the learning } \\
\text { processes according to their } \\
\text { structure, from more structured } \\
\text { and institutionalized, to more } \\
\text { open and unacknowledged by } \\
\text { the participants, according to } \\
\text { Mocker (1983) }\end{array}$ & Formal, Non-formal, Informal, Mixed \\
\hline Educational Level & $\begin{array}{l}\text { Characterization of the educa- } \\
\text { tional level taking into consid- } \\
\text { eration the lifelong learning } \\
\text { spectrum }\end{array}$ & $\begin{array}{l}\text { Early Education and Care, School Primary, } \\
\text { School Secondary, Teacher Education \& } \\
\text { Professional Development, Professional } \\
\text { Learning, Adult Learning }\end{array}$ \\
\hline $\begin{array}{r}\text { Ontological } \\
\text { Definition }\end{array}$ & $\begin{array}{l}\text { The conceptual and empirical } \\
\text { definitions supporting the } \\
\text { construct of LE adopted in the } \\
\text { study }\end{array}$ & $\begin{array}{l}\text { A Space, An Environment, A Metaphor, } \\
\text { Network, Contexts for Learning, Available } \\
\text { Resources, A set of elements (resources, } \\
\text { relationships, activities), A timeline } \\
\text { describing learning transitions, A } \\
\text { learning identity and the expertise on } \\
\text { which it is based, Unclear Ontological } \\
\text { Definition }\end{array}$ \\
\hline
\end{tabular}


Table 1: (Continued)

\begin{tabular}{|c|c|c|}
\hline Fields [Variables] & Description & Subfields [Codes assigned] \\
\hline $\begin{array}{l}\text { Underlying } \\
\text { Theories/ } \\
\text { Models }\end{array}$ & $\begin{array}{l}\text { The most relevant theories } \\
\text { detected in the papers cited, } \\
\text { where present. Variable coded } \\
\text { openly and subfields created } \\
\text { inductively. }\end{array}$ & $\begin{array}{l}\text { Connectivism, Socio-constructivism, } \\
\text { Actor-Network Theory, Self-Directed } \\
\text { Learning, Lifelong Learning, Communities } \\
\text { of Inquiry, Critical Pedagogy, Mixed } \\
\text { Theories, Unclear Theoretical Positioning }\end{array}$ \\
\hline $\begin{array}{l}\text { Methodological } \\
\text { Approach }\end{array}$ & $\begin{array}{l}\text { Methodological choices made by } \\
\text { the authors; codes elaborated } \\
\text { from Raffaghelli, Cucchiara, } \\
\text { and Persico (2015) }\end{array}$ & $\begin{array}{l}\text { Literature Review, Conceptual Paper, } \\
\text { Qualitative Observational, Quantitative } \\
\text { Observational, Mixed Observational, } \\
\text { Qualitative Interventionist, Quantitative } \\
\text { Experimental, Mixed Interventionist, } \\
\text { Unclear Methodological Definition }\end{array}$ \\
\hline $\begin{array}{l}\text { Research } \\
\text { Applications } \\
\text { (Impact) }\end{array}$ & $\begin{array}{l}\text { The extent to which the selected } \\
\text { study envisaged research } \\
\text { applications, derived from the } \\
\text { concept of LE adopted. The } \\
\text { overall concept was based on } \\
\text { Bastow, Tinkler, and Dunleavy } \\
\text { (2014). The type of impact was } \\
\text { derived from discussion }\end{array}$ & $\begin{array}{l}\text { A framework to observe learning processes, } \\
\text { A framework to develop self-diagnosis } \\
\text { empowering learners to engage in lifelong } \\
\text { learning, A framework to develop learning } \\
\text { needs analyses to design educational } \\
\text { interventions, A framework to develop } \\
\text { digital tools and environments for } \\
\text { learning }\end{array}$ \\
\hline \multirow[t]{3}{*}{ Alignment } & \multirow{3}{*}{$\begin{array}{l}\text { The extent to which there is a } \\
\text { powerful relationship between } \\
\text { the definition of LE as a concept, } \\
\text { the empirical research and the } \\
\text { research applications (between } \\
\text { Ontology, Methodological } \\
\text { Approach, Theories and } \\
\text { Research Applications) }\end{array}$} & $\begin{array}{l}\text { Powerful alignment } \\
\text { Good alignment with some weaknesses }\end{array}$ \\
\hline & & Weak alignment \\
\hline & & No alignment \\
\hline
\end{tabular}

experts and four PhD students. As can be observed, the fields identified attempted to capture: (1) the research identity (Authors, Title, Year, Source Title, No. of Citations, DOI, Document Type, Publication Type, Publication Source, Author Keywords, Research Area, Geographical Area); (2) the research focus on learning (Type of Learning, Educational Level, Pedagogical Granularity); (3) the epistemological approach (Ontological Definition, Underlying Theories, Methodological Approach, Research Applications); d) the evaluation of alignment within the epistemological approach (alignment between Ontology, Theories, Methodological Approach, Theories and Research Applications). Some of these categories were shaped on the basis of prior studies, cited in the "Description" column; in any case, they were discussed and adjusted in the above-mentioned session. Table 1 presents the set of categories defined and then validated.

After consolidating the categories, the authors analysed 11 papers (almost 15\% of the overall dataset of 85 papers) and the interrater agreement was calculated.

The Cohen's kappa obtained was 0.63, which can be interpreted as "Substantial Agreement" (0.6 to 0.8 ). One researcher therefore proceeded with the codification of the remaining 74 papers, adopting the criteria discussed within the research group.

The data collected through the database (cf. Table 1) were processed by adopting two techniques: Descriptive univariate and bivariate statistics, adopted to better describe and summarize the numerous variables studied in the literature, according to the classification in Table 1. Finally, a 


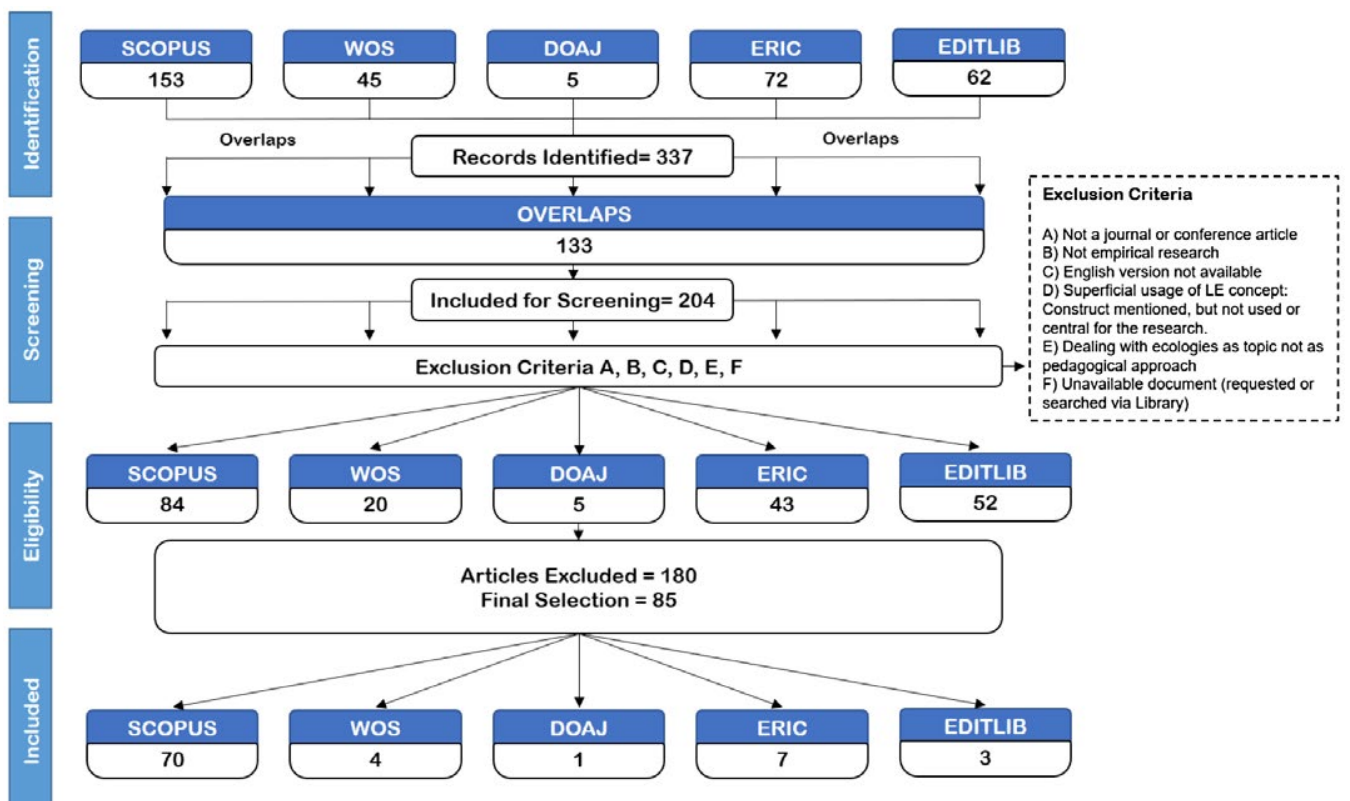

Figure 1: PRISMA workflow-Selection of articles

co-citations map was created. This is based on a text mining technique aimed at understanding the relationships between the citations as the dynamic used in carrying out the research activity about a particular topic (van Eck \& Waltman, 2014). The interpretation of this data would lead us to further characterize the trends in the corpus of literature ( 85 papers) under analysis. The bibliometric maps are based on three main elements: statistical analysis of written publications (often including text and data mining); methods of visualization (distance-based; graph-based; timeline-based) and digital tools supporting analysis and visualization. Not only do the forms of visualization explore a current, static relationship, but they also highlight groups (clusters) that are "closer" within the relationship, as well as their progression, if we take into consideration the timeline. Although bibliometric maps were not developed for conducting literature reviews, the associated techniques and tools allow scientific information about a given field of research to be processed in order to analyse a set of bibliographical references to identify research agglomerates and visualize their connections.

In our research, the total number of citations and the relationships between the authors cited most often and all authors were extracted from the corpus analysed; a specific dataset was created and the outputs were processed using specialized software that delivers the bibliometric maps as output. The software tool, Citenet Explorer (http://www.citnetexplorer.nl/), was used to carry out this phase of the study, which enables the co-citations to be analysed and visualized.

\section{Results}

The results are presented according to the four main categories of analysis explained in the previous section, combining the numerous elements in order to gain a better understanding of the findings. The dataset and a more complete set of dynamic representations of the graphs in this paper are available at Tableau Public (https://tabsoft.co/2JbcP6S). 
As we observe in Figure 2, in 2008 the number of papers increases throughout the period until 2016, and decreases in 2017 and 2018. The number of citations also decreases, which is an effect that can be expected (it takes years to accumulate a number of citations in a publication). The year 2008 yields the highest number of cited papers; taking into consideration the number of papers that year (3), the attention is clearly focused on just a few authors. Moreover, the latest contributions tend to adopt highly diversified sources of reference. Interestingly, the three most cited contributions indeed pertain to three very diverse disciplinary fields: Abd-El-Khalick and Akerson (2004), 148 out of 1991 total citations, whose topic is science education; Barron (2006), 286 out of 1991 citations, whose topic is technological education through a social lens (gender and inclusion in technological fluency); and Gutiérrez (2008), 443 out of 1991 citations, whose field of research is sociolinguistics.

When considering research productivity measured through the number of citations, combined with the type of learning and educational level (showed in Figure 3), we see that most citations can be connected to the study of secondary school education, with 1193 out of 1991 citations (see, eg, Barron, 2004, 2006; Gurung \& Rutledge 2012; Shaw \& Krug 2013), followed by teachers' professional development, with 347 (see, eg, van den Beemt \& Diepstraten 2016); and Higher Education, with 168 (see, eg, Dron, Seidel, \& Litten 2004; Okamoto, Kayama, Cristea, \& Seki 2001) . These are the easiest and most commonly studied levels in educational research, since the subjects are often engaged through institutional programmes or design experiments in class.

However, if we combine this information with the type of learning under study, we can see that in spite of the high level of activity showing the continuum between informal, non-formal and formal learning at secondary school level (1136 citations combining all or at least 2 types of learning), most studies in other levels concentrate on formal contexts and types of learning (343/347 in teachers' professional development; 142/168 in higher education). Interestingly, many papers study learning processes which are informal yet connected to secondary students engaged in formal learning. However, most papers adopt the LE concept whereby it reflects a balance of resources used within a class, where the introduction of digital technologies, or the use of alternative community spaces or time, expands the space or learning environment.

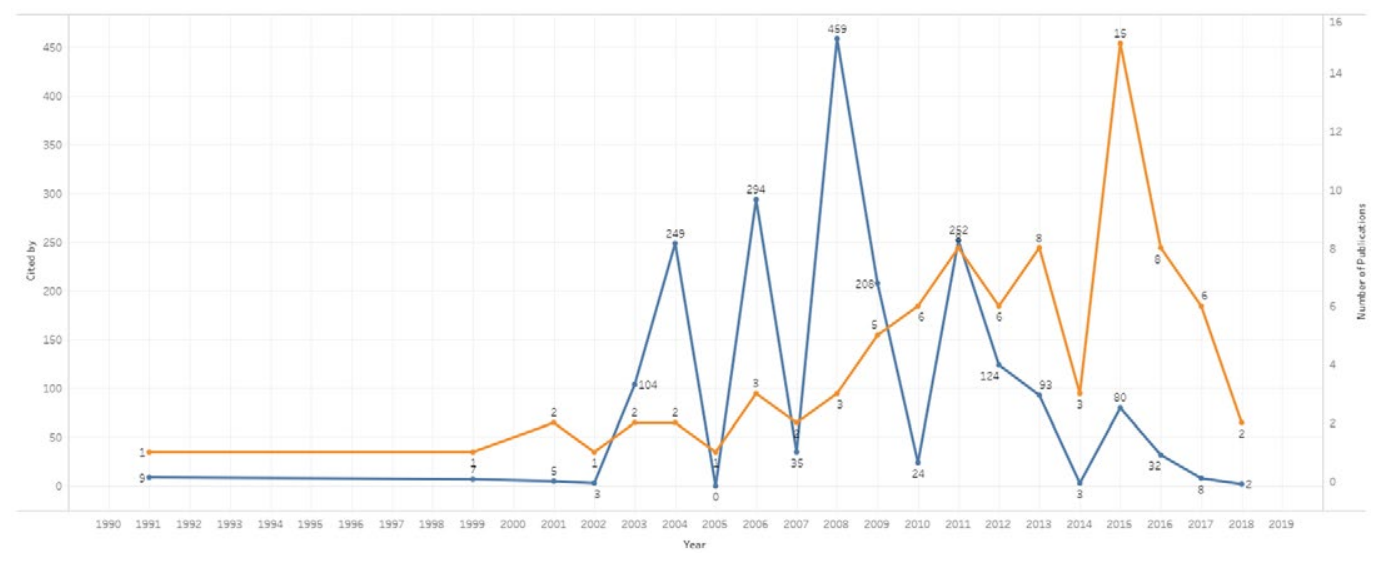

Figure 2: Number of papers per year and number of citations per paper

Note. The scale for number of citations is showed in the left axis and the scale for the number of publications is showed in the right axis; moreover, the two scales are made compatible to allow comparisons. The $X$ axis shows the timeline. 


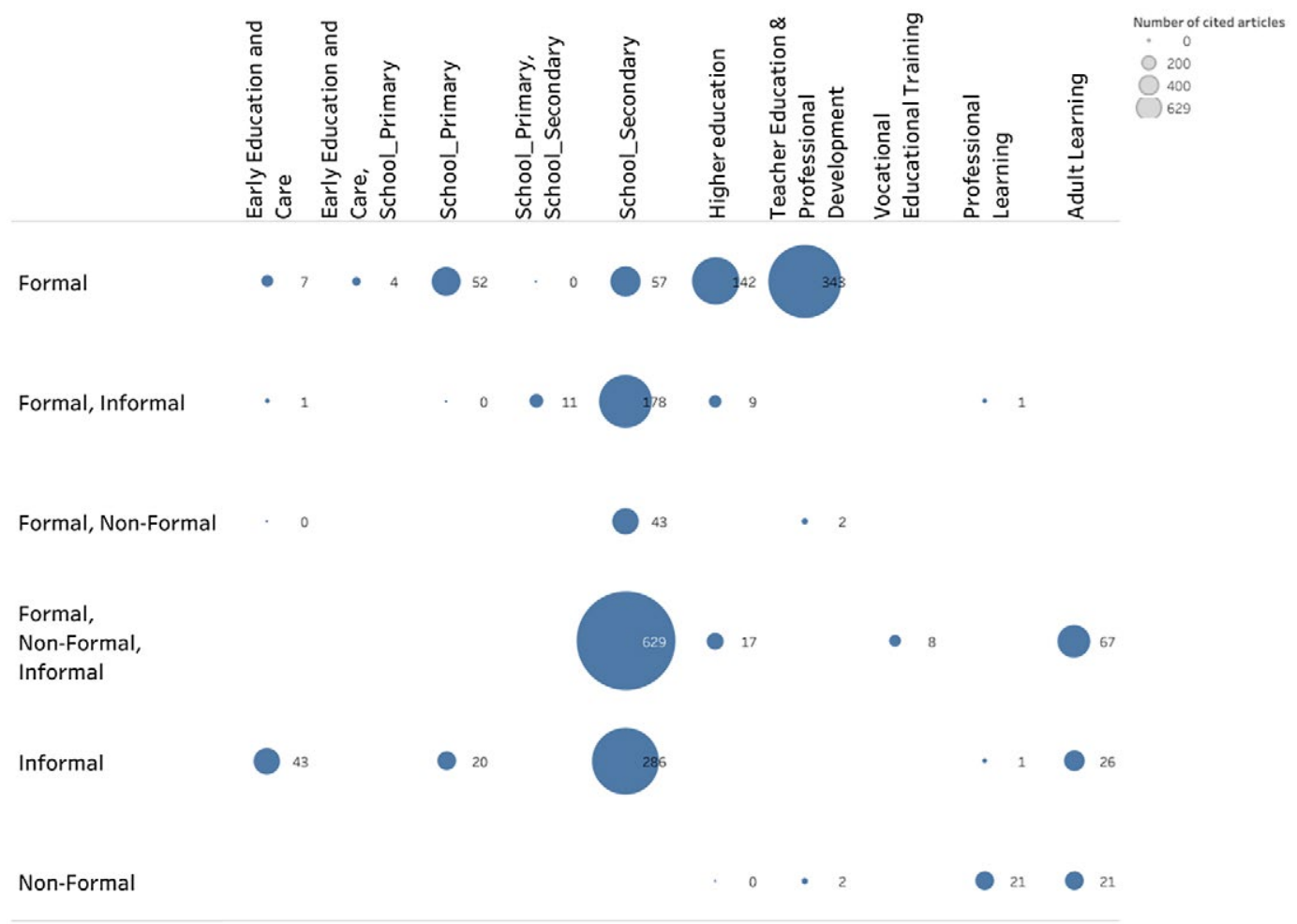

Figure 3: Type of learning $\times$ level of education $\times$ number of citations

Having characterized the research productivity in terms of full citations along the time span considered, as well as per type of learning and level of instruction where the studies were placed, we will now go in-depth by analysing how the LE have been characterized in ontological and methodological terms, as well as from the point of view of research applications. Furthermore, we will consider the issue of alignment between the above-mentioned three attributes (ontology, methodology and research applications). Lastly, we will analyse the co-citations between authors in order to search for recurrent information supporting our assumptions.

\section{Theories in LE research}

As for the theories adopted by the authors, we combined this information with the research areas and the educational level in order to see if there was a pattern in the use of theories (see Figure 4). As expected, most papers examining the research area and educational level adopted socio-constructivism as the main theory to support their work on LE—-see, eg, Jocson (2016) and Hernández-Sellés, González- Sanmamed, \& Muñoz-Carril (2015).

Overall, the use of connectivism can be deemed relevant too (see, eg, Jiménez Cortés 2015; Macleod, Haywood, Woodgate, \& Alkhatnai 2015). However, it should be considered that a significant number of papers were labelled as having an "unclear theoretical definition," and this situation applied particularly to teachers' professional development. It is also clear that the types of theories adopted are very diverse. If we only take into account the research area, it is evident that most papers fall under the area of social sciences and deal with pedagogy rather than with 


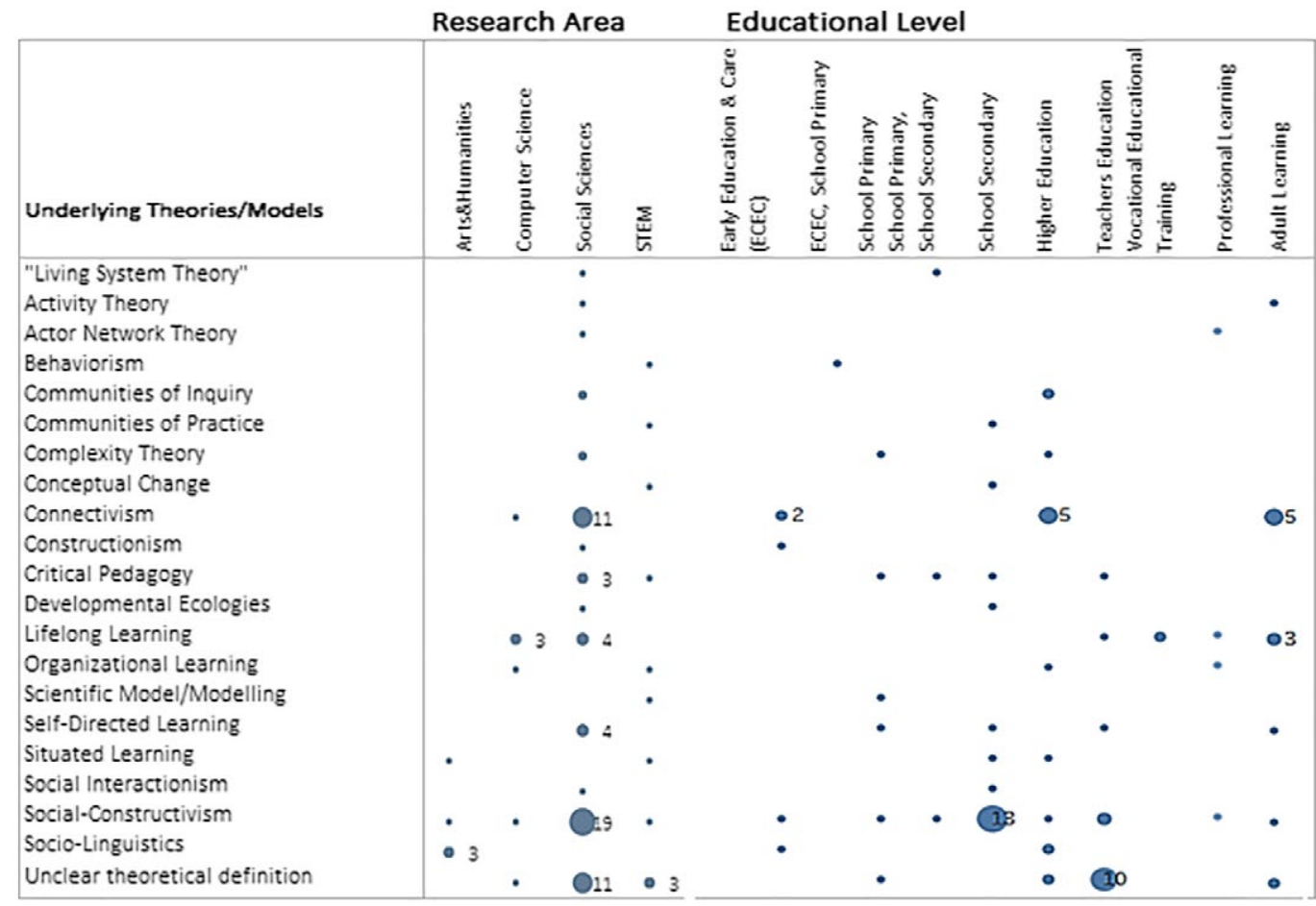

Figure 4: Underlying theories combined with research area and educational level

the specific teaching in a disciplinary field (see, eg, Greenhow \& Robelia 2009; Khau, De Lange, \& Athiemoolam, 2013). However, research has been carried out that adopts the concept of LE in the disciplinary areas of Sociolinguistics, Computer Sciences and STEM—see, eg, Hibbert (2011) for the first area; Tabuenca, Kalz, and Specht (2014) for the second; and Johnston, Southerland, and Sowell (2006) for the third. In all these cases, highly diversified learning theories were used.

Ontological definitions in LE research

We also investigated the ontological definitions adopted by the authors, which should shed light on how LE were conceived as an object of study together with their connected empirical phenomena. We had hypothesized a rather uneven set of definitions. The theories underlying the various studies allowed us to imagine categories, which were theoretically elaborated concepts, to a greater or lesser degree. In fact, "Resources for Learning" "Sets of Elements" or "Learning Environments" (eg, Khau et al., 2013; Okamoto et al., 2001) were less elaborated concepts and were more connected with the empirical phenomena of the technologies available or framing the learner's experience. "Contexts for Learning," on the other hand, could be connected to the socio-constructivist approaches, using the idea of several social contexts (formal, non-formal, informal) where the learner interacts and builds knowledge. In the same vein, the learning ecology considered as a network refers to connectivist studies. While coding, a few other ontological definitions emerged (cf. Table 1), which were aligned with the complex picture already noticed while exploring the theories.

As we observe in Figure 5, consistent with the higher number of studies conducted under the theoretical approach of socio-constructivism, the ontological definition of "Contexts for 


\begin{tabular}{|c|c|c|c|c|c|c|c|c|c|}
\hline \multirow[b]{2}{*}{ Methodological Approach } & \multicolumn{9}{|c|}{ Ontological Definition } \\
\hline & 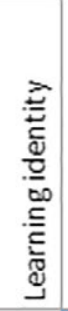 & $\begin{array}{l}\frac{1}{0} \\
\frac{\tau}{0} \\
\frac{0}{0} \\
\Sigma\end{array}$ & 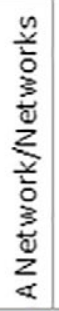 & 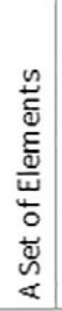 & $\begin{array}{l}\stackrel{\Xi}{0} \\
\text { ஸे } \\
<\end{array}$ & 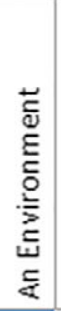 & 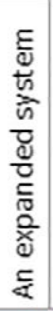 & 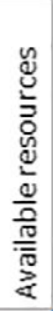 & 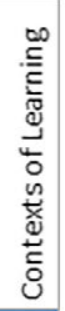 \\
\hline Unclear & & 5 & 1 & 1 & & 6 & 2 & & 6 \\
\hline Conceptual Paper & & 1 & & 4 & & 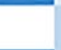 & 3 & & 1 \\
\hline Literature Review & & 2 & & & & 6 & 3 & 3 & 8 \\
\hline Qualitative Observational & & 1 & 1 & 2 & 3 & 2 & & 2 & 1 \\
\hline Quantitative Observational & & & & 1 & & 3 & & & 1 \\
\hline Mixed Observational & & & & 1 & 1 & 3 & & & 1 \\
\hline Qualitative Interventionist & & & & 2 & & & & & 1 \\
\hline Qualitative Experimental & & & & & & & & & 1 \\
\hline Mixed Interventionist & 1 & & 1 & & & 2 & & & 3 \\
\hline
\end{tabular}

Figure 5: Ontological definitions and methodological approaches

Learning" appears in a significant number of studies (22/85), which is, however, identical to the number of studies where the concept of LE is defined as "Environment" (22/85).

\section{Methodological approaches}

When merging the ontological definitions with the Methodological Approaches (cf. Figure 5), more relevant information comes out: most studies, independently of their ontological definition, are executed using conceptual approaches (no empirical research, 24/85; see, eg, Johnston et al., 2006; Okamoto et al. 2001) and exploratory, observational approaches (27/85 as qualitative observational, 10/85 as quantitative, 6/85 as mixed, with observational approaches totalling 43/85). Very few papers adopt experimental/interventionist approaches (14/85 overall; see, eg, Ozan, 2013; Wong 2013), ie, attempting to modulate learner behaviour/opinions as well as to study the educational impacts of interventions. In a research topic spanning 20 years of research, it is to be expected that the construct adopted would tend towards applied educational research (Gorard, 2004).

We could assume here that development in the research field has been very slow, with most papers concentrating on observing and describing a phenomenon (the LE) rather than confirming hypotheses and implementing experimental designs.

Alignment between ontological definitions, methodological approaches and research applications Lastly, we took into consideration the alignment between the theories adopted, the ontological definition of LE and the methodological approach adopted to conduct the various studies. The aim of this focus of analysis related to our assumption that greater alignment could lead to better research quality and usage/applications. Indeed, we considered the alignment together with the research applications. All in all, these two variables could explore the effectiveness of the research in the sense of putting the construct of LE to work, addressing educational 


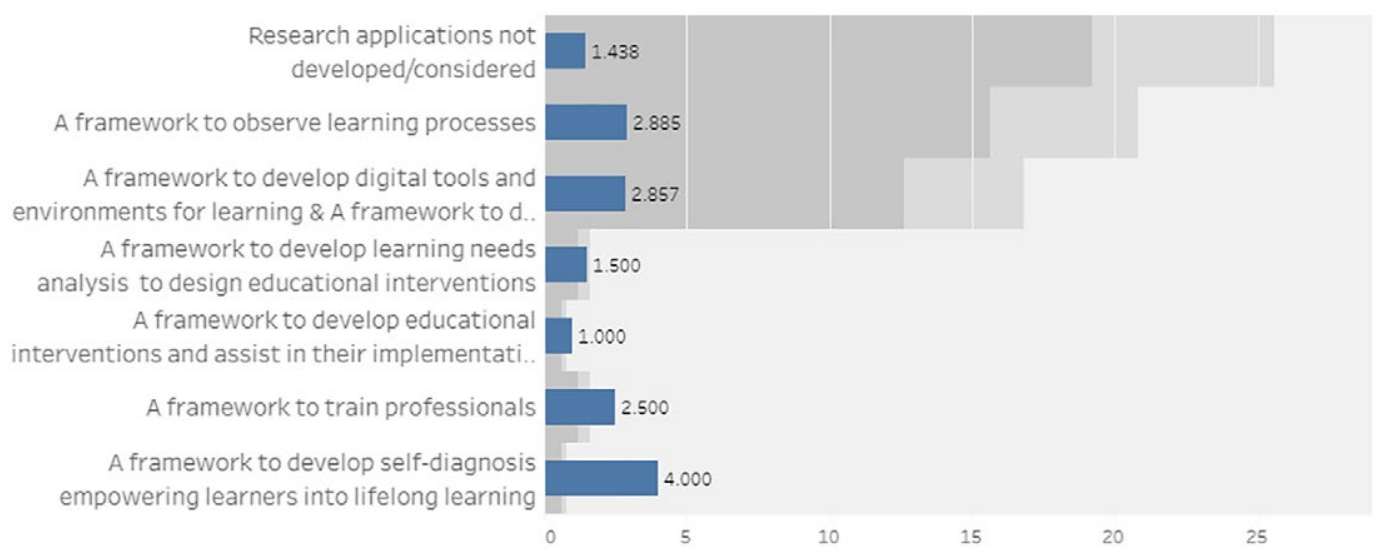

Figure 6: Number of papers and level of theoretical, ontological and methodological alignment Note. The blue bar represents the level of alignment and shows the mean alignment score (Scale $=1-4$, where 1 is no alignment, $2=$ weak alignment, 3 = good alignment with some weaknesses, $4=$ good alignment). The grey bars represent

the number of papers in the category considered (ie, number of papers for "a framework to observe learning processes"). Moreover, $60 \%$ and $80 \%$ of papers are concentrated in just two of the grey bars.

design, teaching and learning processes. Not surprisingly, as shown in Figure 6, LE are mostly connected to conceptual applications, namely, to defining a framework for observing learning processes (27 papers). The research alignment is considered mostly good with some weaknesses (2.89, in a scale from 1 to 4 ). The following category relates to the applications of digital tools and environments for learning (21), also rated mostly good with weaknesses (2.86). The third place is given to a high number of papers not defining any type of research application (32) where the alignment could be deemed weak (1.44). The few remaining papers consider other types of application, such as defining learning needs analyses (two papers, with weak alignment [1.5]), defining educational interventions and assisting their implementation (one paper, with weak alignment) and a framework for training professionals (two papers, with good alignment with weaknesses [2.5]). One paper developed a self-diagnosis approach to empowering lifelong learners that had an excellent level of alignment (4.00). This scenario supports the prior findings of a concentration of conceptual and observational studies, where the research applications have not been neatly developed. Hence, while the observational approaches exploring and describing LE prevail, the more "designerly" ways of research are almost non-existent.

\section{Integrative analysis: Co-citations map}

The last type of analysis conducted on the papers sampled was the co-citations map. This was adopted as a method to gain a better understanding of the relationships and progress made in work relating to the concept of LE. Figure 7 shows the co-citations map, where, at first sight, two main groups of nodes or authors cited (X axis) can be observed across a time span (Y axis), with sparse elements at the centre and the beginning of the period (1991). The main and more compact group (also in terms of clusterization of nodes, which are shown in green) related to the publications that cite the seminal work of Barron (2004). These publications are mostly classified as using socio-constructivist theories and are placed in the area of social sciences, while other categories (such as the methodological approach and research applications and alignment) are more fragmented). There are four seminal works (Abd-El-Khalick \& Akerson, 2004; Barron, 


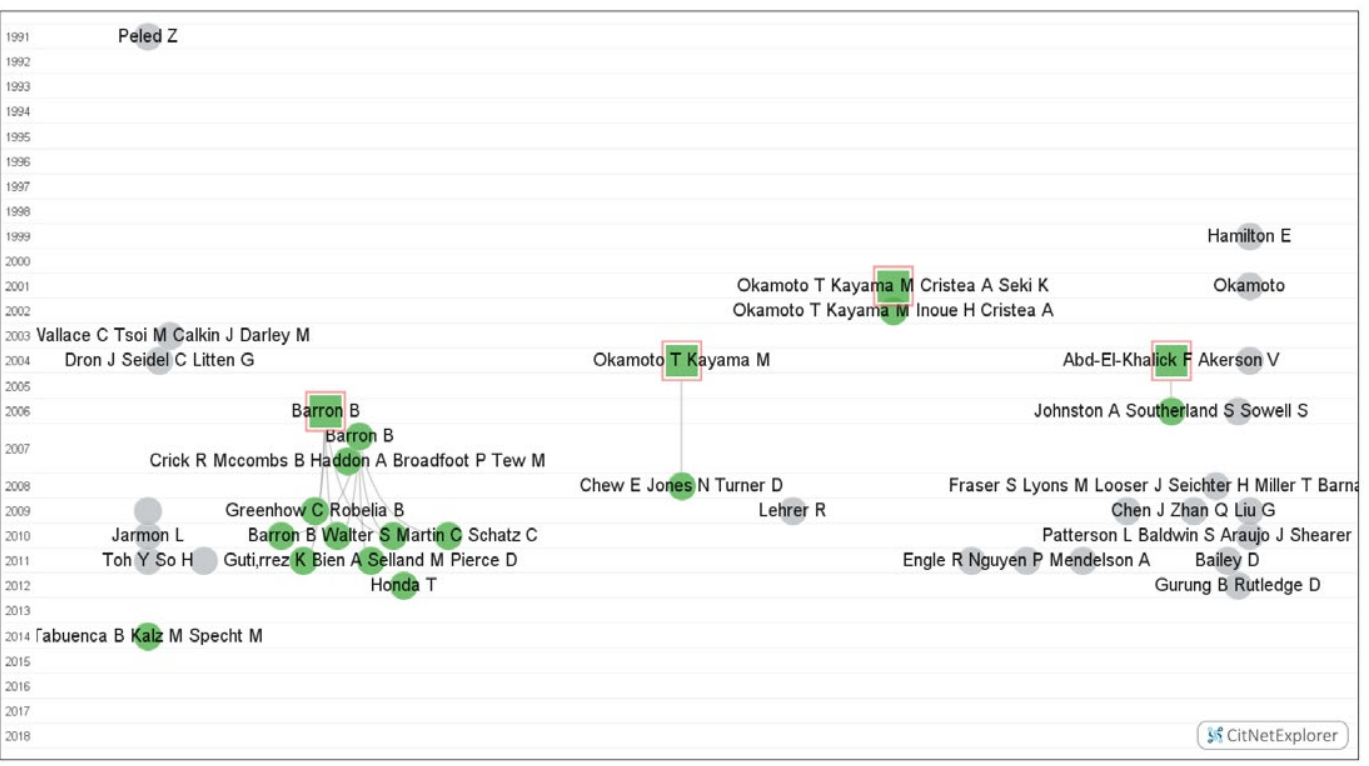

Figure 7: Co-citations map

2004; Okamoto, \& Kayama, 2004; Okamoto, Kayama, Inoue, \& Cristea, 2002) to which other papers can be connected. Beyond the aforementioned work of Barron, the other three works can be placed in the area of technology (development of e-learning environments) and STEM education, supporting the idea of disciplinary fragmentation.

\section{Discussion and conclusions}

In our systematic review of the literature, we focused on three essential elements shaping the development of LE as a research topic. These elements were the conceptual definition or the ontological perspective addressed by several studies, the methodological approaches and the applications of the research to several educational services, process, practices, etc. These three elements were combined with dimensions characterizing the theories adopted and the disciplinary field or area of research as well as the context from which the empirical evidence was taken, such us the educational level and type of learning.

According to our analysis of 85 papers, we observed, firstly, that research in this field is growing at a slow but constant pace; however, there are some imbalances between the papers produced and coherent patterns of citation. While some of the works in the field are highly visible, others are somewhat submerged. This element, combined with other factors, shows a rather fragmented field where the concept of LE could be said to be polysemic. As a matter of fact, the many theoretical approaches emerging, in spite of the small number of papers that focus on socio-constructivism combined with the secondary level and connectivism in higher education and adult learning, as well as the many ontological and methodological approaches observed, support the hypothesis of fragmentation. Another important piece of evidence in this sense was the co-citations map, which showed separated areas of research (STEM/computational focus and sociotechnical approaches). This form of fragmentation is quite usual, especially in fields that are multi- or interdisciplinary, as is the case with educational technologies and e-learning (Sangrà, Guàrdia, \& González-Sanmamed, 2006) 
With regard to contexts where empirical evidence was generated, it must be highlighted that most studies focused on the educational level of secondary education, in spite of interesting analysis observing the combinations of formal learning in class with informal learning activities complementary to the school. This situation aligns with the trend identified by Zawacki-Richter and Latchem (2018), whose paper revisiting 40 years of research in educational technologies found that most empirical research had been conducted on this educational level. It is evident that studies analysing the continuum between formal and informal learning in higher education and adult education, as well as vocational educational training are still needed. Moreover, most research dealing with professional learning focused on teachers' professional development (TPD), with studies investigating formal learning processes within TPD activities; this result can evidently be connected to the facilitated access to formal contexts of learning (such as school and teacher education). This picture appears to show that the full potential of the concept of LE remains unexploited. From the background literature analysed, it was made clear that people adopt technologies to flow across several experiences of learning, cultivating relationships and curating resources, and analyses focusing mainly on formal spaces show a very limited picture of these lifelong learning continuums. However, the research analysed to date does not seem to provide strong evidence for research applications produced by educational interventions that make use of the concept of learning ecology. It seems clear that there is a need for further research to identify patterns that could lead to better educational designs in several fields-materials, resources, applications, guidance, etc.-across digital and physical contexts of learning to promote the visibility and development of LE. In fact, since most studies are exploratory and observational, the analysis is limited to describing or explaining an existing LE, and this is the case of studies with good alignment (even if there are no research applications, but the ontological and methodological principles are in line with each other). However, the poor alignment observed in many studies seems to show that the concept is adopted only as an initial metaphor.

Going a step further, a number of authors have acknowledged the importance of making LE visible (Esposito et al., 2015; Hernández-Sellés et al., 2015; Patterson, Baldwin, Araujo, Shearer, \& Stewart, 2010), but, in line with the low alignment observed, very few studies provide designbased research that tests educational interventions based on the idea of the visibility of LE. Visibility of LE is especially important to make learners aware of their LE. As Argyris (1974) stated, reflection is a key aspect of increasing the learning capabilities through double loop learning (acquiring specific skills and reflecting on the same achievements). Moreover, as Blaschke (2012) states, the visibility of LE can promote learner empowerment in self-determining their own lifelong learning pathways (Jackson, 2016). In fact, the concept of LE could combine self-determined learning as a motivation for learning in the mid and long term, and self-directed learning as a motivation and direction of learning across immediately available contexts. Nonetheless, as we observed throughout the fragmentation of ontological perspectives, poor operational definitions hinder developments connected to visibility, indicating a possible way forward for future research. For example, one promising area of research could be connected to multimodal analytics based on learners' activities in several learning contexts; the dashboards that help represent learners' own LE; and the opportunities for development. In this regard, the multiple apps helping learners to track activities in informal situations beyond the classroom could represent a new way of thinking about how learning processes bridge the formal and informal continuum along a timeline. However, if the research conducted on the basis of sociotechnical approaches is never linked to research in the computational sciences, it will be impossible to bridge pedagogical concepts and technological developments; this is a concern if we consider the situation of research on LE as described in this paper. 
Our study is limited in offering a perspective of what LE are or could actually be, but we have tried to show the criticalities that prevent progress in research on this topic being made due to its fragmentation and lack of educational applications. Furthermore, while the topic has advanced discussions on conceptual basis, as it is the case of Jackson contribution through his books and online resources, our aim here was to show the problems of alignment between concepts and empirical research. This might be seen as a limitation on the study scope, ie, in covering the whole universe of scholarly work on LE. However, it was a necessary step to achieve the systematic review's goal. It is clear that the growing interest in LE clearly demonstrates the attention paid by researchers to the need to overcome rigid separations between formal and informal learning, the digital and the physical, the pedagogical and the technological. A more rigorous conceptual and empirical alignment of research efforts would encompass clearer advancement towards models capable of characterizing patterns of ecological growth and maintenance, tools supporting the visibility of learning processes across contexts and tools to self-diagnose one's own LE and characterize the LE of specific professional or disciplinary groups, etc. Although the current situation does not address this potential, and the results of the systematic review suggest few current educational applications, there are some scenarios that could be considered promising. On one hand, there are a number of ongoing studies that could provide interesting contributions to the field from very different topics of research. Studies that focus on the learning ecologies of entrepreneur mothers (Johnson, 2018) online higher education students (Peters, 2018); media communication professionals (Bruguera, 2018); which try to identify patterns on learners' decisions and their inner motivations to learn, have the potential to support learning design for these emergent collectives, taking into consideration preferred and new resources that could result in new learning opportunities.

On the other hand, different methodological approaches can be envisaged: research-based designs resulting in frameworks and artefacts that could be used for self-diagnosis supporting learners' awareness raising on their learning ecologies; longitudinal studies that could provide a wider picture of the learning ecologies of specific collectives and their lifespan approaches to learning, etc. In the current landscape, new data-driven techniques and Artificial Intelligence could provide new tools to analyse the learning ecologies not only for diagnosis, but also with predictive and proactive approaches. However, more in-depth and extensive research on the topic is required, as LE could become a lens for seeing how people organize their means of learning more clearly, namely, how they make decisions on what and how to learn. For learners' autonomy and freedom entails the richest forms of learning, and it is the educational endeavour to capture and support such forms without limitating them. This is the potential enclosed in the construct of Learning Ecologies.

\section{Acknowledgements}

The authors wish to thank the colleagues of Edul@b for the insightful discussions about the concept of learning ecologies; and to the research assistant Alicia Puig Fernández, for her valuable contribution. This research has been parcially funded by the Project "Ecologías de aprendizaje a lo largo de la vida: contribuciones de las TIC al desarrollo profesional del profesorado" (Eco4Learn) Spanish Ministry of Economy and Competitiveness I+D (EDU2012-37334); the project "Cómo aprenden los mejores docentes universitarios en la era digital: Impacto de las ecologías de aprendizaje en la calidad de la enseñanza (ECO4LEARN-HE), Spanish Ministry of Economy and Competitiveness I+D (EDU2015- 67907-R) and the Project "Professional learning ecologies for Digital Scholarship: Steps for the Modernisation of Higher Education”, Spanish Ministry of Economy and Competitiveness, Programme "Ramón y Cajal” RYC-2016-19589. 


\section{Statements on open data, ethics and conflict of interest}

The data processed and analysed in this paper is openly shared as Open Data. The main dataset has been published on Tableau Public, allowing the interested reader to take a look at dynamic visualizations. Moreover, there is a copy of data at Zenodo, added in this paper as reference (Fernández \& Raffaghelli, 2018; Raffaghelli \& Fernández, 2018). The data can be used and shared citing the original work. All the information contained in the datasets is public and does not refer to sensitive information.

The whole research project ECO4Learn is compliant with the UOC's institutional Ethics Committee guidelines.

The authors declare no conflicts of interest.

\section{References}

Abd-El-Khalick, F., \& Akerson, V. L. (2004). Learning as conceptual change: Factors mediating the development of preservice elementary teachers' views of nature of science. Science Education, 88(5), 785-810. https://doi.org/10.1002/sce.10143

Argyris, C. (1974). Behind the front page. San Francisco, CA: Jossey Bass.

Attwell, G. (2007). Personal learning environments - The future of eLearning? Lifelong Learning, 2(January), 1-8. Retrieved from http://www.elearningeuropa.info/files/media/media11561.pdf

Barron, B. (2004). Learning ecologies for technological fluency: Gender and experience differences. Journal of Educational Computing Research, 31(1), 1-36. https:/doi.org/10.2190/1N20-VV12-4RB5-33VA

Barron, B. (2006). Interest and self-sustained learning as catalysts of development: A learning ecology perspective. Human Development, 49, 193-224. https://doi.org/10.1159/000094368

Bastow, S., Tinkler, J., \& Dunleavy, P. (2014). The impact of the social sciences: How academics and their research make a difference. London, UK: SAGE.

Bateson, G. (1987). Steps to an ecology of mind. Collected essays in anthropology, psychiatry, evolution, and epistemology. Northvale, NJ: Jason Aronson Inc. https://doi.org/10.2307/446833

Blaschke, L. M. (2012). Heutagogy and lifelong learning: A review of heutagogical practice and self determined learning. International Review of Research in Open and Distance Learning, 13(1), 56-71. https://doi. org/10.1016/j.system.2004.09.015

Bronfenbrenner, U. (1994). Ecological models of human development. Readings on the Development of Children. Retrieved from http://www.psy.cmu.edu/ siegler/35bronfebrenner94.pdf

Bruguera, C. (2018). The opportunities of social media for professional development: An exploration of the learning ecologies of digital communicators. 10th EDEN Research Workshop, Barcelona, 24-26 October, 2018.

Crick, R. D., Mccombs, B., Haddon, A., Broadfoot, P., \& Tew, M. (2007). The ecology of learning: Factors contributing to learner-centred classroom cultures. Research Papers in Education, 22(3), 267-307. https:// doi.org/10.1080/02671520701497555

Cross, J. (2006). Informal learning: Rediscovering the natural pathways that inspire innovation and performance. San Francisco, CA: Pfeiffer.

Dabbagh, N., \& Kitsantas, A. (2012). Personal learning environments, social media, and self-regulated learning: A natural formula for connecting formal and informal learning. Internet and Higher Education, 15(1), 3-8. https://doi.org/10.1016/j.iheduc.2011.06.002

Díez-Gutiérrez, E., \& Díaz-Nafría, J.-M. (2018). Ubiquitous learning ecologies for a critical cybercitizenship. Comunicar, 26(54), 49-58.

Dron, J., Seidel, C., \& Litten, G. (2004). Transactional distance in a blended learning environment. ALT-J, 12(2), 163-174. https://doi.org/10.1080/0968776042000216219

Esposito, A., Sangrà, A., \& Maina, M. F. (2013). Chronotopes in learner-generated contexts. A reflection about the interconnectedness of temporal and spatial dimensions to provide a framework for the exploration of hybrid learning ecologies of doctoral e-researchers. ELearn Center Research Paper Series. Retrieved from http://journals.uoc.edu/index.php/elcrps/article/view/1868/n6-esposito-ePub 
Esposito, A., Sangrà, A., \& Maina, M. F. (2015). Emerging learning ecologies as a new challenge and essence for e-learning. In M. Ally, \& B. Khan (Eds.), International handbook of e-learning volume 1: Theoretical perspectives and research (pp. 331-342). London, UK: Routledge. https://doi.org/10.4324/9781315760933

Fernández, A. P., \& Raffaghelli, J. E. (2018). Co-citations map: Literature review on learning ecologies, 1991-2018. Zenodo. https://doi.org/10.5281/ZENODO.1506173

Gorard, S. (2004). Combining Methods in Educational and Social Research. Maidenhead, UK: Open University Press - McGraw Hill Education.

Greenhow, C., \& Robelia, B. (2009). Informal learning and identity formation in online social networks. Learning, Media and Technology, 34(2), 119-140. https://doi.org/10.1080/17439880902923580

Gurung, B., \& Rutledge, D. (2012). Developing and implementing technology-integrated Triad model in content areas for alternative students: An exploratory study. Society for Information Technology \& Teacher Education International Conference (Vol. 2012). AACE.

Gutiérrez, K. D. (2008). Developing a sociocritical literacy in the third space. Reading Research Quarterly, 43(2), 148-164.

Haythornthwaite, C., \& Andrews, R. (2011). e-Learning ecologies. In E-learning theory and practice (pp. 143-160). London, UK: SAGE. https://doi.org/10.4135/9781446288566.n9

Hernández-Sellés, N., González- Sanmamed, M., \& Muñoz-Carril, P.-C. (2015). Teacher's roles in learning ecologies: Looking into collaborative learning in virtual environments. Profesorado, Revista de Currículum y Formación del Profesorado (Vol. 19). FORCE.

Hibbert, L. (2011). Language development in higher education: Suggested paradigms and their applications in South Africa. Southern African Linguistics and Applied Language Studies, 29(1), 31-42. https://doi. org/10.2989/16073614.2011.583089

Hodgson, A., \& Spours, K. (2009). Collaborative local learning ecologies: Reflections on the governance of lifelong learning in England (Report). Leicester: National Institute of Adult Continuing Education.

Ige, O. A. (2017). Rethinking students' dispositions towards civic duties in urban learning ecologies. International Journal of Instruction, 10(4), 307-324.

Jackson, N. (2013). The concept of learning ecologies. In N. Jackson, \& B. Cooper (Eds), Lifewide learning, education \& personal development (chapter A5). Retrieved from http://www.lifewideebook.co.uk/conceptual.html

Jackson, N. (2016). Exploring learning ecologies. Betchworth, Surrey: Chalk Mountain. ISBN 978-0-9935759-0-7

Jiménez Cortés, R. (2015). Aprendizaje ubicuo de las mujeres jóvenes en las redes sociales y su consciencia de aprendizaje. Prisma Social: Revista de investigación social, ISSN-e 1989-3469, No. 15, 2015 (Ejemplar dedicado a: Tecnologías Móviles en la Educación y Sociedad Actual), (pp. 180-221). Fundación iS+D para la investigación Social Avanzada.

Jocson, K. M. (2016). "Put Us on the Map": Place-based media production and critical inquiry in CTE. Qualitative Studies in Education, 29(10), 1269-1286. https://doi.org/10.1080/09518398.2016.1192698

Johnson, N. (2018). Capacity development through informal learning: An exploration of the digital learning ecologies of Canadian female entrepreneurs. 10th EDEN Research Workshop, Barcelona, 24-26 October, 2018.

Johnston, A., Southerland, S. A., \& Sowell, S. (2006). Dissatisfied with the fruitfulness of "learning ecologies”. Science Education, 90(5), 907-911. https://doi.org/10.1002/sce.20161

Kamenetz, A. (2010). Edupunks, edupreneurs, and the coming trasformation of higher education. White River, VT: Chelsea Green.

Khau, M., De Lange, N., \& Athiemoolam, L. (2013). Using participatory and visual arts-based methodologies to promote sustainable teaching and learning ecologies: Through the eyes of pre-service teachers. The Journal for Transdisciplinary Research in Southern Africa, 9(3), 12. https://doi.org/10.4102/td.v9i3.187

Kimmons, R., \& Veletsianos, G. (2018). Public internet data mining methods in instructional design, educational technology, and online learning research. TechTrends, 62(5), 492-500. https://doi.org/10.1007/ s11528-018-0307-4

Kop, R., \& Fournier, H. (2010). New dimensions to self-directed learning in an open networked learning environment. International Journal of Self-Directed Learning, 7(2), 1-20. Retrieved from http://sdlglobal. com/IJSDL/IJSDL7.2-2010.pdf \#page $=6$ 
Kop, R., Fournier, H., \& Mak, J. S. F. (2011). A pedagogy of abundance or a pedagogy to support human beings? Participant support on massive open online courses. International Review of Research in Open and Distance Learning, 12(7), 74-93.

Luckin, R. (2010). Re-designing learning contexts. Technology-rich, learner-centred ecologies. London: Routledge.

Macleod, H., Haywood, J., Woodgate, A., \& Alkhatnai, M. (2015). Emerging patterns in MOOCs: Learners, course designs and directions. TechTrends, 59(1), 56-63. https://doi.org/10.1007/s11528-014-0821-y

Maina, M. F., \& González, I. G. (2016). Articulating personal pedagogies through learning ecologies. In B. Gros, Kinshuk, \& M. Maina (Eds.), The future of ubiquitous learning (pp. 73-94). Hershey, PA: IGI-GLOBAL. https://doi.org/10.1007/978-3-662-47724-3_5

Mocker, D. W. (1983). Lifelong learning: Formal, nonformal, informal, and self-directed. Adult Education, 33(4), 260. https://doi.org/10.1177/0001848183033004009

Moher, D., Liberati, A., Tetzlaff, J., Altman, D. G. \& PRISMA Group. (2009). Preferred reporting items for systematic reviews and meta-analyses: The PRISMA statement. PLoS Medicine, 6(7), e1000097. https:// doi.org/10.1371/journal.pmed.1000097

Okamoto, T., \& Kayama, M. (2004). A collaborative environment for new learning ecology and e-pedagogy. In A. Tatnall, J. Osorio, \& A. Visscher (Eds.), Information technology and educational management in the knowledge society (pp. 161-170). Boston, MA: Kluwer Academic Publishers. https://doi. org/10.1007/0-387-24045-4_15

Okamoto, T., Kayama, M., Cristea, A., \& Seki, K. (2001). The distance ecological model to support self/ collaborative-learning in the Internet environment. In Proceedings - IEEE International Conference on Advanced Learning Technologies, ICALT 2001 (pp. 418-421). IEEE Computer Society. https://doi. org/10.1109/ICALT.2001.943963

Okamoto, T., Kayama, M., Inoue, H., \& Cristea, A. I. (2002). The integrated e-learning system RAPSODY based on distance ecology model and its practice. Journal of Educational Technology \& Society, 5(4), $124-136$.

Ozan, O. (2013). Scaffolding in connectivist mobile learning environment. Turkish Online Journal of Distance Education, 14(2), 44-55. https://doi.org/10.4324/9780203118764.ch15

Patterson, L., Baldwin, S., Araujo, J., Shearer, R., \& Stewart, M. A. (2010). Look, think, act: Using critical action research to sustain reform in complex teaching/learning ecologies. Journal of Inquiry and Action in Education, 3(3), 139-157.

Peters, M. (2018). The contribution of digital online higher education: Student engagement in the continuum between formal and informal learning. 10th EDEN Research Workshop, Barcelona, 24-26 October, 2018.

Petticrew, M., \& Roberts, H. (2006). Systematic reviews in the social sciences. A practical guide. Oxford, UK: Blackwell.

Raffaghelli, J. E., Cucchiara, S., \& Persico, D. (2015). Methodological approaches in MOOC research: Retracing the myth of Proteus. British Journal of Educational Technology, 46(3), 488-509. https://doi. org/10.1111/bjet.12279

Raffaghelli, J. E., \& Fernández, A. P. (2018). Systematic review on the research topic learning ecologies Dataset and analysis. Zenodo. https://doi.org/10.5281/ZENODO.1503775

Richardson, A. (2002). An ecology of learning and the role of eLearning in the learning environment (Global Summit). Auckland. Retrieved from http://unpan1.un.org/intradoc/groups/public/documents/apcity/ unpan007791.pdf

Sangrà, A., Guàrdia, L., \& González-Sanmamed, M. (2006). Educational design as a key issue in planning for quality improvement. In M. Bullen, \& D. P. Janes (Eds.), Making the transition to e-learning: Strategies and issues (pp. 284-299). Hershey, PA: IGI Global. https://doi.org/10.4018/978-1-59140-950-2.ch017

Sangrà, A., González-Sanmamed, M., \& Guitert, M. (2013). Learning ecologies: Informal professional development opportunities for teachers. In 2013 IEEE 63rd Annual Conference International Council for Education Media (ICEM) (pp. 1-2). https://doi.org/10.1109/CICEM.2013.6820171

Selwyn, N. (2011). Editorial: In praise of pessimism-the need for negativity in educational technology. British Journal of Educational Technology, 42(5), 713-718. https://doi.org/10.1111/j.1467-8535.2011.01215.x 
Sharples, M. (2015). Seamless learning despite context. In L. H. Wong, M. Milrad, \& M. Specht (Eds.), Seamless learning in the age of mobile connectivity (pp. 41-55). Singapore, Singapore: Springer. https://doi. org/10.1007/978-981-287-113-8_2

Shaw, A., \& Krug, D. (2013). Youth, heritage, and digital learning ecologies: Creating engaging virtual museum spaces. Conference on Educational Media and Technology. EdMedia + Innovate Learning (Vol., 2013), AACE.

Siemens, G. (2008). New structures and spaces of learning: The systemic impact of connective knowledge, connectivism, and networked learning. In Encontro sobre Web 2.0. Braga, Portugal: Universidade do Minho. Retrieved from http://elearnspace.org/Articles/systemic_impact.htm

Strohmayer, A., Comber, R., \& Balaam, M. (2015, April). Exploring learning ecologies among people experiencing homelessness. In Proceedings of the 33rd Annual ACM Conference on Human Factors in Computing Systems (pp. 2275-2284). ACM.

Tabuenca, B., Kalz, M., \& Specht, M. (2014). Tap it again, Sam: Harmonizing the frontiers between digital and real worlds in education. In 2014 IEEE Frontiers in Education Conference (FIE) Proceedings (pp. 1-9). IEEE. https://doi.org/10.1109/FIE.2014.7044000

van den Beemt, A., \& Diepstraten, I. (2016). Teacher perspectives on ICT: A learning ecology approach. Computers \& Education, 92-93, 161-170. https://doi.org/10.1016/J.COMPEDU.2015.10.017

Van Eck, N. J., \& Waltman, L. (2014). Visualizing bibliometric networks. In Y. Ding, R. Rousseau, \& D. Wolfram (Eds.), Measuring scholarly impact: Methods and practice (pp. 285-320). Cham, Switzerland: Springer.

Virtanen, M. A., Haavisto, E., Liikanen, E., \& Kääriäinen, M. (2018). Ubiquitous learning environments in higher education: A scoping literature review. Education and Information Technologies, 23(2), 985-998. https://doi.org/10.1007/s10639-017-9646-6

Wilkinson, J., Kemmis, S., Hardy, I., \& Edwards-Groves, C. (2009). Leading and learning: Developing ecologies of educational practice. Australian Association for Research in Education International Conference. Retrieved from https://espace.library.uq.edu.au/view/UQ:209939

Wong, L.-H. (2013). Analysis of students' after-school mobile-assisted artifact creation processes in a seamless language learning environment. Journal of Educational Technology \& Society, 16(2), 198-211.

Wong, L. H., Milrad, M., \& Specht, M. (2015). Seamless learning in the age of mobile connectivity. Singapore, Singapore: Springer. https://doi.org/10.1007/978-981-287-113-8

Zawacki-Richter, O., \& Latchem, C. (2018). Exploring four decades of research in Computers \& Education. Computers \& Education, 122, 136-152. https://doi.org/10.1016/J.COMPEDU.2018.04.001

\section{Supporting Information}

Additional supporting information may be found online in the Supporting Information section at the end of the article. 